\title{
Device Problem
}

National Cancer Institute

\section{Source}

National Cancer Institute. Device Problem. NCI Thesaurus. Code C54026.

Medical device failure or malfunction associated with device functions, including any deviations from documented specifications, requirements, and intended uses. 